\title{
Timely Diagnosis of Malalignment of the Distal Extremities Is Crucial in Morbidly Obese Juveniles
}

\author{
Franz Landauer ${ }^{a}$ Gerda Huber $^{b} \quad$ Katharina Paulmichl $^{b} \quad$ Grace O'Malley $^{c}$ \\ Harald Mangge ${ }^{d}$ Daniel Weghuber ${ }^{b}$ \\ a Department of Orthopedics, ${ }^{b}$ Department of Pediatrics, Paracelsus Medical University, \\ Salzburg, Austria, ' ${ }^{\mathrm{D}}$ Departments of Endocrinology and Physiotherapy, Temple Street \\ Children's University Hospital, Dublin, Ireland, 'Clinical Institute of Medical and Chemical \\ Laboratory Diagnosis, Medical University of Graz, Graz, Austria
}

\author{
Key Words \\ Obesity $\cdot$ Children $\cdot$ Malalignment $\cdot$ Lower extremities $\cdot$ Temporary epiphyseodesis
}

\begin{abstract}
Background/Aims: To determine i) whether obesity in childhood can be related to malalignment of the distal extremities, ii) the proportion of genu valgum malalignment and abduction setting, and iii) the respective deviation dominance in children who are morbidly obese. Methods: 31 morbidly obese Caucasian children (16 males) recruited for the STYJOBS Study (ClinicalTrials.gov Identifier NCT00482924) with a mean age of $13.9 \pm 0.5$ years, a mean height of $162.3 \pm 2.7 \mathrm{~cm}$, a mean weight of $90.62 \pm 5.0 \mathrm{~kg}$, and a mean BMI of $33.8 \pm 1.2 \mathrm{~kg} / \mathrm{m}^{2}$ were clinically examined using the Mikulicz line in order to assess load distribution on the knee joint. 21 participants received a whole-leg X-ray because of a clinically estimated malalignment. Results: $8 / 31$ participants examined were diagnosed with genu valgum, 1/31 with genu varum, and 22/31 did not have any malalignment of the femur or tibia. The majority of genu valgum presentation was due to femoral deviation. Of those without malalignment, 4/22 participants had an abduction setting, while $2 / 22$ showed an adduction of the leg. Conclusion: Genu valgum as a predominant malalignment of the distal extremities is frequent in youth with morbid obesity. Timely guided correction of angular deformity of the knee seems pivotal in order to avoid osteotomy or osteoarthritis later in life.

(c) 2013 S. Karger $\mathrm{GmbH}$, Freiburg
\end{abstract}


Landauer et al.: Timely Diagnosis of Malalignment of the Distal Extremities Is Crucial in Morbidly Obese Juveniles

\section{Introduction}

Childhood obesity is associated with a wide spectrum of medical comorbidities of significant physical and psychological impact [1]. The individual and financial costs associated with musculoskeletal conditions are substantial [2], and musculoskeletal pain has been identified as the most expensive of all disease categories in Europe [3].

Recently, obesity has been acknowledged as a key risk factor for musculoskeletal problems in children and adolescents. Obese children have an increased fracture risk [4], suffer more frequently from back, hip, and knee pain [4-6], and present with more impaired flexibility [7], changes in foot structure [8, 9], osteoarthritis [10-12], slipped capital femoral epiphysis [13], and Blount's disease [14] compared to normal-weight individuals. Lower extremity malalignment, which might predispose to osteoarthritis [10], has also been suggested to be highly prevalent in obese children $[4,5,7,15]$.

However, no studies have yet assessed these patients regarding the clinical distinction of actual malalignment from the mere abduction setting of the leg, which can be challenging in daily routine, particularly in morbidly obese patients. In addition, there is a lack of data on the prevalence and the extent of femoral and tibial deviation in malaligned extremities. This is relevant because a timely diagnosis may have immediate therapeutic implications in juveniles.

Therefore, the current study aims to determine i) whether obesity in childhood is related to malalignment of the distal extremities, ii) the proportion of genu valgum malalignment and abduction setting of the leg, and iii) the respective deviation dominance (i.e. femoral vs. tibial) in morbidly obese children.

\section{Subjects and Methods}

The study population consisted of morbidly obese Caucasian children recruited for the STYrian Juvenile Obesity Study (STYJOBS; ClinicalTrials.gov Identifier NCT00482924) at the Department of Pediatrics, Paracelsus Medical School Salzburg, Austria, from March 2007 to May 2011. None of the patients were referred for orthopedic reasons. All patients were morbidly obese, defined as a BMI > 99.5 percentile for age and sex [16], and aged between 6 and 19 years. The subjects enrolled were apparently healthy based on a complete physical examination. Exclusion criteria were chronic rheumatic disease, major trauma, or fracture of the distal extremities leading to their malalignment. 31 subjects ( 16 males) were eligible for evaluation (table 1). Oral consent from all participants as well as parental consent for minors was obtained.

\section{Anthropometric Measurements}

Height, weight, and waist circumferences were obtained from all children. The participants wore light clothing (e.g. shorts and a light top) and no shoes during the measurements. Standing height was measured to the nearest $0.1 \mathrm{~cm}$ using a portable calibrated stadiometer (SECA). Body mass was measured to the nearest $0.01 \mathrm{~kg}$ using calibrated electronic scales (SECA 701). The BMI was calculated as the weight in kilograms divided by the square of height in meters $\left(\mathrm{kg} / \mathrm{m}^{2}\right)$. The degree of overweight was quantified by using Cole's least mean square method, which normalizes the BMI-skewed distribution and expresses BMI as a standard deviation (SD) score (BMI-SDS). Waist circumference was measured in a standing position with a flexible tape midway between the lower costal margin and the superior border of the iliac crest.

\section{Clinical Orthopedic Examination}

As described by Westhoff etal. [17], the distal extremities were assessed in the frontal plane by observing the standing participant from the front and from the back. The assessment of lower limb alignment, however, can be challenging in patients with excessive subcutaneous fat accumulation. Thus, the Mikulicz line was used in order to evaluate the alignment of the lower extremities. This method was originally designed to objectively assess limb alignment using long-leg X-rays [18]. In this study, the patient was positioned in supine position with outstretched legs for the initial clinical assessment. Using a piece of rope, the top end was posi- 
Landauer et al.: Timely Diagnosis of Malalignment of the Distal Extremities Is Crucial in Morbidly Obese Juveniles

Table 1. Clinical characteristics of study participants $(n=31)$
Total cohort

$\begin{array}{ll}\text { Age, years } & 13.9 \pm 0.5 \\ \text { Body height, cm } & 162.3 \pm 2.7 \\ \text { Body weight, kg } & 90.6 \pm 5.0 \\ \text { BMI, kg/m }{ }^{2} & 33.8 \pm 1.2 \\ \text { BMI-SDS } & 2.78 \pm 0.09 \\ \text { Waist circumference, cm } & 105.9 \pm 3.9\end{array}$

BMI-SDS = Body mass index standard deviation score.

tioned two square fingers medial to the superior anterior iliac spine and was drawn to the talocrural articulation, thereby clinically reproducing the Mikulicz line. If the rope was passing centrally through the knee, indicating a physiological burden of the joint, an abduction setting of the knee was diagnosed. If the line passed medially to the patella or medially to the intercondylar eminentia of the tibia, the setting was interpreted as genu varum; the line passing laterally to the patella was interpreted as genu valgum. In cases of clear or suspected malalignment, an anteroposterior weight-bearing long-leg X-ray was performed to distinguish between actual misalignment of the extremity and abduction setting of the leg, and to determine the respective degree of misalignment/abduction setting, as previously described by Strecker [19]. A $1^{\circ}$ physiologic variation of the mechanical weight-bearing axis from the center of the knee joint and a $1^{\circ}$ error in measurement was assumed. All subjects displaying an axial deviation $>2^{\circ}$ were diagnosed as genu valgum or genu varum [20]. This value is in accordance with the SD of the tibiofemoral angle, as previously reported [21-23]. In cases of malalignment, the axial deviation was also used to determine the deviation dominance (i.e. femoral vs. tibial). For this, the anatomic lateral distal femoral angle (aLDFA) and medial proximal tibial angle (MPTA) were used to describe the axes between knee joint line and the related anatomic axes in the frontal plane defined by a line drawn through the diaphyseal shaft of the femur/tibia [19]. The physiologic norm for these angles was defined as 85-90 (MPTA) and 79-83 (aLDFA) [19]. A deviation in one of the two angles indicated the center of rotation of angulation (CORA) of the malalignment.

\section{Results}

The clinical characteristics of the study participants are given in table 1. Data are given as means and SD. All patients were morbidly obese.

\section{Alignment of Distal Extremities}

$10 / 31(32.3 \%)$ patients showed normal alignment of the distal extremities upon physical examination, requiring no X-ray. According to investigational standards of the Orthopedic Department of the University Hospital Salzburg, an X-ray was only taken if the Mikulicz line was not centered at the patella or if the iliac crest could not be detected due to abdominal mass $(21 / 31$ patients $=67,7 \%)$. In 12 of these individuals $(12 / 31=38.7 \%)$, no malalignment could be diagnosed radiographically (with 4 patients showing an abduction setting and 2 an adduction setting). 8/31 (25.8\%) patients showed genu valgum and $1 / 31$ (3.2\%) genu varum (table 2).

\section{Mechanical Axis Deviation}

In $6 / 8$ (i.e. $75 \%$ ) participants, genu valgum malalignment was due to femoral malalignment, in $1(12.5 \%)$ individual due to tibial malalignment, whereas in $1(12.5 \%)$ participant combined malalignment of femur and tibia was detected. Of the participants without malalignment, 4/12 (33.3\%) had an abduction setting and 2/12 (16.7\%) an adduction of the leg (table 2). The mechanical axis deviation from the center of the knee in patients with 
Landauer et al.: Timely Diagnosis of Malalignment of the Distal Extremities Is Crucial in Morbidly Obese Juveniles

Table 2. Alignment of the distal extremities (31 participants)

\section{n}

$\begin{array}{ll}\text { Anatomical malalignments } & \\ \text { Genu valgum } & 8 \\ \text { Femur } & 6 \\ \text { Tibia } & 1 \\ \text { Femur + tibia } & 1 \\ \text { Genu varum } & 1\end{array}$

\begin{tabular}{ll}
\hline No anatomical pathology & \\
Clinical diagnosis (Mikulicz line central) & 10 \\
Radiographic diagnosis & 12 \\
Abduction of knee $>2^{\circ}$ to plumb line & 4 \\
Adduction of knee $>2^{\circ}$ to plumb line & 2 \\
\hline
\end{tabular}

Table 3. Mechanical axis deviation from the center of the knee

\begin{tabular}{llll}
\hline & $\begin{array}{l}\text { Mean mechanical axis } \\
\text { deviation }\end{array}$ & aLDFA & MPTA \\
\hline $\begin{array}{l}\text { Genu valgum }(\mathrm{n}=8) \\
\text { Right leg }\end{array}$ & $3.3 \pm 0.8^{\circ}\left(2.5-4.7^{\circ}\right)$ & $78.2 \pm 3.7^{\circ}\left(73.9-85.6^{\circ}\right)$ & $88.2 \pm 1.3^{\circ}\left(86-89.5^{\circ}\right)$ \\
Left leg & $3.4 \pm 1.4^{\circ}\left(2.1-5.8^{\circ}\right)$ & $79.3 \pm 4.6^{\circ}\left(72-85.7^{\circ}\right)$ & $87.7 \pm 1.8^{\circ}\left(84-90^{\circ}\right)$ \\
Genu varum $(\mathrm{n}=1)$ & $3.9^{\circ}$ & $85.6^{\circ}$ & $88.1^{\circ}$ \\
Right leg & & & \\
\hline
\end{tabular}

aLDFA = Anatomic lateral distal femoral angle (reference 79-83 [19]); MPTA = medial proximal tibial angle (reference $85-90^{\circ}[19]$ ).

genu valgum malalignment ranged from 2.5 to $4.7^{\circ}$ on the right side and from 2.1 to $5.8^{\circ}$ on the left side. There was 1 participant demonstrating genu varum malalignment who showed a deviation of $3.9^{\circ}$ of the right knee.

The aLDFA ranged from 73.9 to $85.6^{\circ}$ on the right leg and from 72 to $85.7^{\circ}$ on the left side. The aLDFA of the participant with genu varum malalignment was $85.6^{\circ}$. The MPTA on the right side ranged from 86 to $89.5^{\circ}$ and from 84 to $90^{\circ}$ on the left side. The MPTA of the participant with genu varum malalignment was $88.1^{\circ}$ (table 3 ).

\section{Therapeutic Consequences}

Of all overweight and obese juveniles with radiographically confirmed genu valgum and genu varum, 5/9 (55.6\%) were recommended to undergo surgical therapy in terms of temporary epiphyseodesis using a tension plate [24]. The other participants with malalignments were either suffering from only slight malalignment $(1 / 9$, i.e. $11.1 \%)$ or complete closure of the growth plates (3/9, i.e. 33.4\%). All patients were referred to interdisciplinary obesity treatment.

\section{Discussion}

This cross-sectional study assessed 31 obese pediatric patients and found that valgus malalignment with femoral deviation is frequent in morbidly obese juveniles. Early diagnosis of lower extremity malalignment seems to be crucial in obese youth in order to allow for 
Landauer et al.: Timely Diagnosis of Malalignment of the Distal Extremities Is Crucial in Morbidly Obese Juveniles

temporary epiphysiodesis as well as to prevent them from osteotomy and, most importantly, irreversible osteoarthritis in later life. Interestingly, femoral deviation was more common than tibial deviation in our morbidly obese pediatric patients. This seems crucial as it might imply direct therapeutic consequences in terms of surgical axis correction and temporary epiphyseodesis.

Children and adolescents who are overweight and especially those who are obese suffer from a multitude of orthopedic complications including musculoskeletal discomfort, spinal complications such as scoliosis or lumbar hyperlordosis, slipped capital femoral epiphysis, osteoarthritis, Blount's disease, bone fractures [5, 13, 25, 26], structural changes of plantar anatomy [8], reduction in flexibility, impaired mobility, and malalignment of the lower extremities $[4,5,7]$.

Among other factors, joint alignment has been described to be vital for osteoarticular health of the knee [27]. About $50 \%$ of severely obese adults (mean BMI $39.9 \pm 5.8 \mathrm{~kg} / \mathrm{m}^{2}$ ) presented with marked lesions of the cartilage of the knee in an Australian study [28]. More importantly, a recent study demonstrated that morbidly obese children and adolescents with knee pain already showed marked morphological changes of the cartilages of different grades and in different compartments of the knee [29].

In general, there are two categories of hypotheses to explain the obesity-osteoarthritis relationship: metabolic and mechanical. A possible relationship between metabolic parameters of obesity and adult osteoarthritis could not be established. Yet, different paradigms have been suggested in which obesity increases the risk of osteoarthritis directly or by influencing local factors that mediate the mechanical impact of excess body weight on the knee [11]. While axial loading, as represented by BMI, was shown not to contribute to the increasing knee angles in normal, healthy-weight children [30], the results of our study confirm our assumption of a high prevalence of malalignments of the distal extremities in morbid obesity as early as during childhood. Even though there is a paucity of literature demonstrating the relationship between body mass and the magnitude of the knee angles in juveniles, our findings are in accordance with previous studies [4, 5]. However, while Taylor et al. [4] used non-weight-bearing images, full-limb X-ray pictures of the lower extremity under weight-bearing conditions with the participants in standing position were used in the current study. These conditions are more likely to reveal the clinically relevant static effect of excess weight loaded on misaligned knees. In keeping with Taylor et al. [4], the majority of our young patients with malalignment showed genu valgum. This is in contrast to adult data where most obese patients exhibit varus rather than valgus alignment [31]. Tayler et al. [4] hypothesized that even mild malalignment might lead to skeletal discomfort and pain if children are overweight or obese. In the development of the lower extremity axis, vertical pressure leads to growth, bone formation, and alignment. This value is in accordance with genu varum, is gradually aligned, and then leads to genu valgum, which reaches its maximum at the age of 3 years and decreases to normal values at around 9 years of age. Most studies on lower limb alignment in children have used the tibiofemoral angle to describe angular deformities of the tibia or femur in the frontal plane [21-23], thus depicting the anatomical axis. However, the mechanical load is best described by the mechanical axis based on the joint reference lines of the hip, knee, and ankle [32].

Given these facts, we hypothesize that overweight might not only decrease mobility and flexibility in children but may also interfere with the natural development of the bone axis so that valgus malalignment persists in a subset of patients. Thus, early-onset obesity before puberty might be a particular risk factor for malalignment and consequent orthopedic complications. There are recent data available showing that structural and physiological changes such as alterations in passive joint restraints occur during puberty. These may not only affect the type, severity, and incidence of injuries in the maturing adolescent population but also contribute to decreased mobility and flexibility in overweight children [33]. 

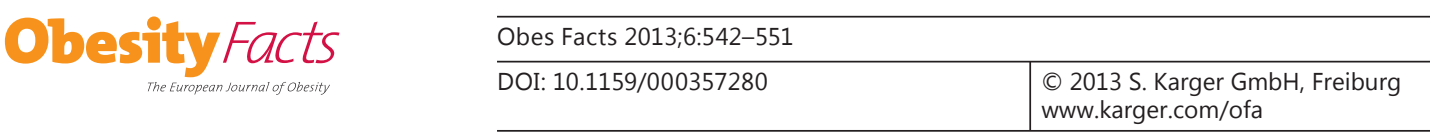

Landauer et al.: Timely Diagnosis of Malalignment of the Distal Extremities Is Crucial in Morbidly Obese Juveniles
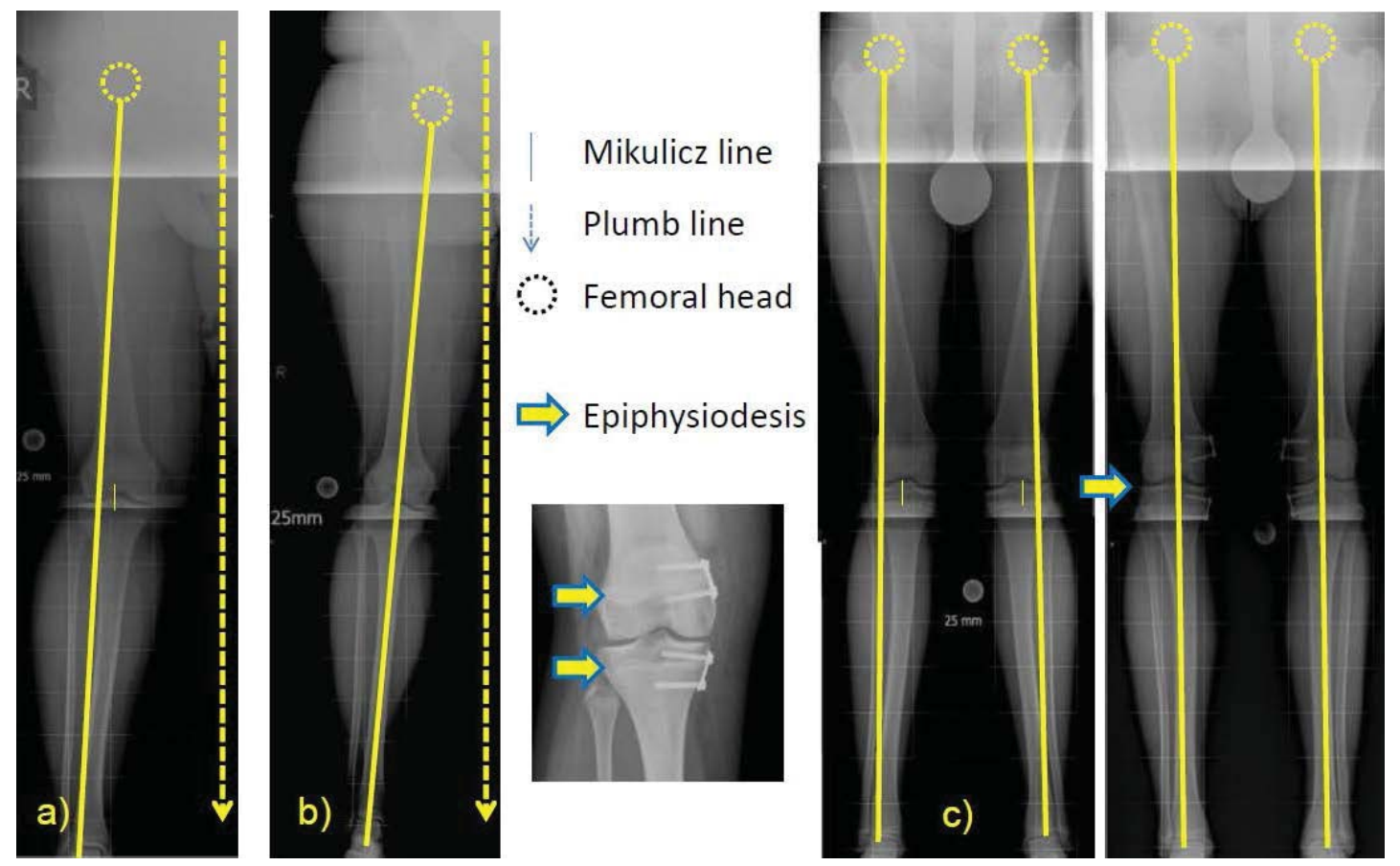

Fig. 1. Clinical presentation of alignment in morbidly obese children. a Genu valgum. b Abduction setting. c Epiphysiodesis to correct genu valgum (prior to and 17 months after surgery).

Due to a lack of prospective studies the long-term clinical significance of childhood knee malalignment associated with obesity has yet to be determined. However, since obesity may increase the magnitude of joint loading, joint position and alignment may influence knee-joint forces. The latter have been theorized to play a pivotal role in the progression of osteoarthritis in the obese by altering stress distribution within the joint [27]. Gushue et al. [34] and Strutzenberger et al. [35] found that obese children have greater knee moments, causing greater loading of the musculoskeletal structures compared to normal-weight children. However, Felson et al. [10] concluded that the effect of BMI might be limited to knees in which at least moderate malalignment exists. Since knee alignment has been shown to influence pain and functional deficits in adult patients with knee osteoarthritis [36], a recent long-term study assessing the relationship between BMI throughout a lifetime and knee pain in adulthood is of great interest: Macfarlane et al. [37] demonstrated that being overweight in teenage years and early adulthood is predictive of knee pain at the age of 45. In addition, a recent study could show that valgus malalignment increases the risk of knee osteoarthritis as assessed by $\mathrm{X}$-ray progression as well as the incidence of lateral cartilage damage [38]. In contrast, it was reported that BMI was positively associated with the severity of joint space narrowing in individuals with varus alignment but not in those with valgus alignment when determined by full-limb radiographs in adults [11]. Westhoff et al. [17] also found that valgus alignment is less likely to cause arthritis than varus alignment.

The growth potential of the distal femur has been shown to be superior as compared to the proximal tibial physis [39]. To the best of our knowledge, we are the first to report that femoral deviation is more common than tibial deviation in obese pediatric patients. Therefore, the differentiation in tibial/femoral predominance of malalignment seems crucial as this might imply direct therapeutic consequences in terms of surgical axis correction and temporary epiphyseodesis $[40,41]$. 


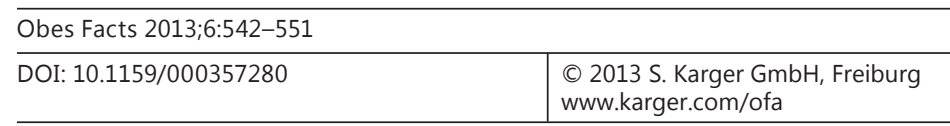

Fig. 2. Algorithm for the orthopedic assessment and treatment of morbidly obese juveniles.

Landauer et al.: Timely Diagnosis of Malalignment of the Distal Extremities Is Crucial in Morbidly Obese Juveniles

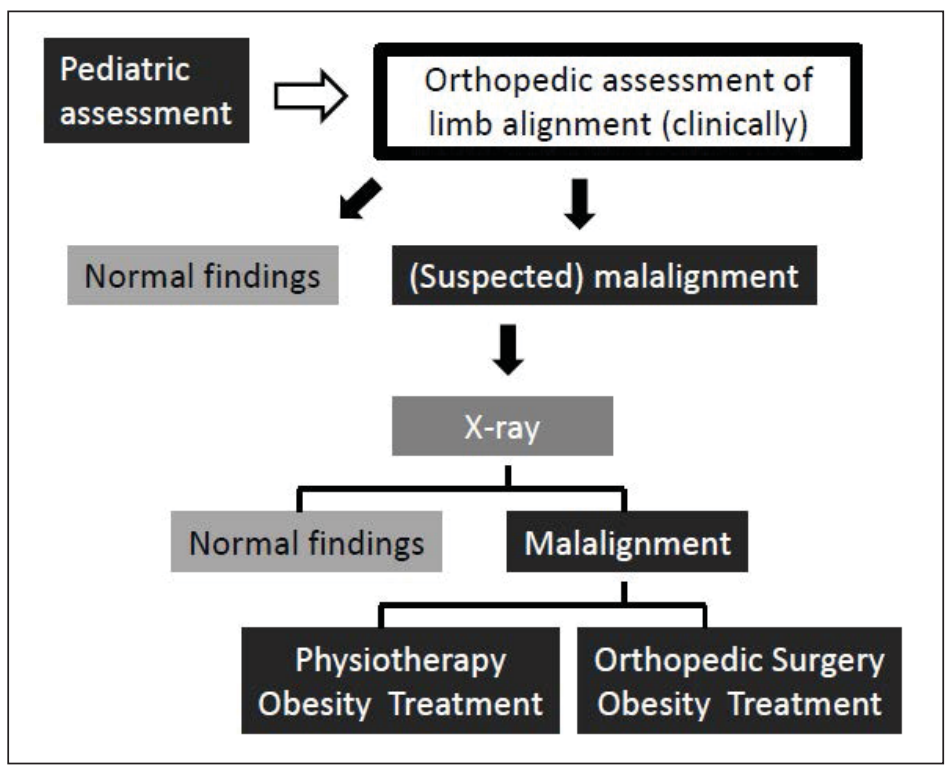

Of the participants in our study without malalignment, about one third was diagnosed with an abduction or adduction setting of the legs. These children showed a physiologic mechanical axis on full-limb X-ray and a normal burden of the knee joint. Under daily clinical conditions the differentiation between mere abduction setting and actual pathologic alignment can be difficult in morbidly obese patients (fig. 1). Although the Mikulicz line is commonly used to interpret lower limb alignment in long-leg X-rays, its clinical depiction by the use of a rope offers a simple screening method in order to differentiate malalignment and abduction setting. However, this is only possible in a minority of morbidly obese juveniles due to difficulties in identifying the respective anatomic landmarks, thus making an X-ray necessary. Moreover, long-leg X-ray pictures allow for defining the degree of severity of malalignment, which is important for surgical treatment decision. However, this method has some limitations. Obesity might pose a problem in diagnosing X-ray pictures and defining anatomic landmarks because of blurred pictures of the femoral head. By holding up abdominal aprons or depicting the femoral head separately, this problem can be avoided.

In our opinion, the results of our study are of utmost clinical relevance: Almost a third of all obese juveniles assessed had a degree of valgus malalignment resulting in referral for surgical correction. In addition, some patients showed closure of the epiphyseal plate and would also have benefited from timely intervention. Diagnosis prior to closure of the epiphyseal plate allows for the comparably simple intervention of epiphyseodesis as compared to osteotomy after further maturation of the bones. While it is common consensus that timely measures to prevent early-onset cardiovascular complications of childhood obesity are necessary [42,43], an equivalent claim seems to be necessary to allow for early diagnosis and swift treatment where knee malalignment is concerned. Current recommendations relating to the assessment of obese children lack detailed guidance for primary and secondary care as far as orthopedic comorbidities are concerned [44, 45]. Although our data can only be regarded as preliminary, the following clinical algorithm seems to deserve further studies: Juveniles who are morbidly obese should undergo a thorough orthopedic assessment including evaluation of lower limb alignment at the beginning of puberty (fig. 2). In the case of suspected or definite malalignment, referral to a pediatric orthopedic specialist for further evaluation seems mandatory to allow for timely surgical intervention if necessary. In any 
Fig. 3. Clinical presentation of lower extremity malalignment in obese children prior to closure of epiphyseal plates and treatment consequences.

Landauer et al.: Timely Diagnosis of Malalignment of the Distal Extremities Is Crucial in Morbidly Obese Juveniles

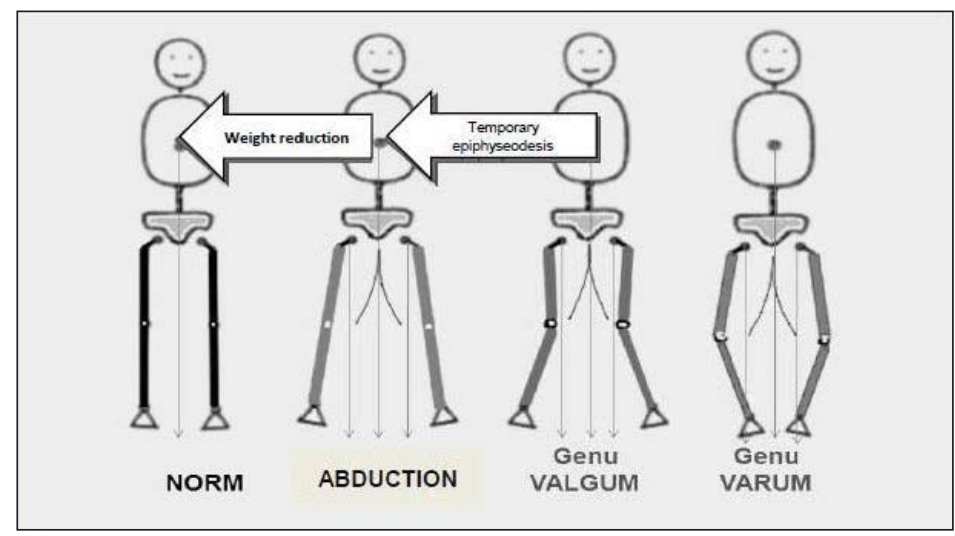

case, effective obesity treatment - including bariatric surgery if indicated - must be initiated (fig. 3) $[45,46]$. However, weight loss has been shown to be difficult to achieve in obese children [47]. Nonetheless, Widhalm et al. [29] proposed that pediatric patients who are obese require professional care concerning musculoskeletal disorders and most importantly physical activity programs adapted to the child's needs, skills, and handicaps. Similarly, Shultz et al. [48] stated that obese children need well-prescribed physical activity programs with less weight-bearing activities. Restoring correct lower limb alignment thus constitutes a prerequisite for knee-joint-friendly physical activity.

There are limitations to our study that need to be acknowledged. Firstly, the small study population prevents us from drawing statistically relevant conclusions regarding the prevalence of malalignment and of the specific types of deviations in general. However, the main conclusions of our study are significant but call for larger studies to obtain further information. Secondly, we cannot exclude referral bias. Most patients were sent to our clinic for metabolic assessment and not due to pain or for orthopedic evaluation.

In conclusion, morbidly obese children frequently suffer from substantial malalignment in need of correction. It is essential that children who are obese receive an accurate assessment of the musculoskeletal system in order to screen for such malalignments to identify those who might require further intervention. Obese children who are showing signs of malalignment should partake in weight management as early as possible in order to avoid progression to pathological deformity requiring surgical correction. Finally, children who are obese and have pathological malalignment should undergo early surgical intervention to achieve axial correction prior to closure of the epiphyseal plates. This might prevent children from undergoing osteotomy and experiencing further complications.

\section{Acknowledgements}

We gratefully acknowledge the help of the staff of the Department of Radiology, Paracelsus Medical School Salzburg, and thank the participating patients and their parents.

\section{Disclosure Statement}

The authors have no potential conflicts of interest to disclose. 
Landauer et al.: Timely Diagnosis of Malalignment of the Distal Extremities Is Crucial in Morbidly Obese Juveniles

\section{References}

Daniels SR: The consequences of childhood overweight und obesity. Future Child 2006;1:47-67.

Lee P: The economic impact of musculoskeletal disorders. Qual Life Res 1994;3:85-91.

Lindgren B: The economic impact of musculoskeletal disorders. Acta Orhop Scand Suppl 1998;281:58-60.

Taylor ED, Theim KR, Mirch MC, Ghorbani S, Tanofsky-Kraff M, Adler-Wailes DC, Brady S, Reynolds JC, Calis KA, Yanovski JA: Orthopedic complications of overweight in children and adolescents. Pediatrics 2006;117: 2167-2174.

$>5$

de Sá Pinto AL, de Barros Holanda PM, Radu AS, Villares SM, Lima FR: Musculoskeletal findings in obese children. J Paediatr Child Health 2006;42:341-344.

6 Stovitz SD, Pardee PE, Vazquerez G, Duval S, Schwimmer JB: Musculoskeletal pain in obese children and adolescents. Acta Paediatr 2008;97:489-493.

7 O'Malley G, Hussey J, Roche E: A pilot study to profile the lower limb musculoskeletal health in children with obesity. Pediatr Phys Ther 2012;24:292-298.

8 Mickle KJ, Steele JR, Munro BJ: The feet of overweight and obese young children: are they flat or fat? Obesity 2006;14:1949-1953.

-9 Pfeiffer M, Kotz R, Ledl T, Hauser G, Sluga M: Prevalence of flat foot in preschool-aged children. Pediatrics 2006;18:634-639.

10 Felson DT, Goggins J, Niu J, Zhang Y, Hunter DJ: The effect of body weight in progression of knee osteoarthritis is dependent on alignment. Arthritis Rheum 2004;50:3904-3909.

11 Sharma L, Lou C, Gahue S, Dunlop DD: The mechanism of the effect of obesity in knee osteoarthritis - the mediating role of malalignment. Arthritis Rheum 2000;43:568-575.

12 Felson DT, Lawrence RC, Dieppe PA, Hirsch R, Helmick CG, Jordan JM, Kington RS, Lane NE, Nevitt MC, Zhang Y, Sowers M, McAlindon T, Spector TD, Poole AR, Yanovski SZ, Ateshian G, Sharma L, Buckwalter JA, Brandt KD, Fries JF: Osteoarthritis: new insights. Part 1: the disease and its risk factors. Ann Intern Med 2000;133: 635-646.

13 Poussa M, Schlenzka D, Yrjönen T: Body mass index and slipped capital femoral epiphysis. J Pediatr Orthop B 2003;12:369-371.

14 Greene WB: Infantile tibia vara. J Bone Joint Surg Am 1993;75:130-143.

15 Gettys FK, Jackson JB, Frick SL: Obesity in pediatric orthopaedics. Orthop Clin North Am 2011;42:95-105.

16 Kromeyer-Hauschild K, Wabitsch M, Kunze D, Geller F, Geiß HC, Hesse V, von Hippel A, Jaeger U, Johnsen D, Korte W, Menner K, Müller G, Müller JM, Niemann-Pilatus A, Remer T, Schaefer F, Wittchen HU, Zabransky S, Zellner K, Ziegler A, Hebebrand J: Percentiles of body mass index in children and adolescents evaluated from different regional German studies (in German). Monatsschr Kinderheilkd 2001;149:807-818.

$\checkmark 17$ Westhoff B, Wild A, Krauspe R: Entwicklung der Beinachse im Kindesalter und Therapieoptionen bei kniegelenksnahen Fehlstellungen. Orthopädie 2002;12:1198-1209.

-18 El-Azab HM, Morgenstern M, Ahrens P, Schuster T, Imhoff AB, Lorenz SG: Limb alignment after open-wedge high tibial osteotomy and its effect on the clinical outcome. Orthopedics 2011;34:622-628.

19 Strecker W: Planning analysis of knee-adjacent deformities. I. Frontal plane deformities. Eur J Trauma Emerg Surg 2007;33:662-668.

20 Paley D: Principles of Deformity Correction. Berlin, Springer, 2002.

21 Salenius P, Vankka E: The development of the tibiofemoral angle in children. J Bone Joint Surg Am 1957;57: 259-261.

-22 Arazi M, Ogün TC, Memik R: Normal development of the tibiofemoral angle in children: a clinical study of 590 normal subjects from 3 to 17 years of age. J Pediatr Orthop 2001;21:264-267.

23 Kaspiris A, Zaphiropoulou C, Vasiliadis E: Range of variation of genu valgum and association with anthropometric characteristics and physical activity: comparison between children aged 3-9 years. J Paediatr Orthop B 2013;22:296-305.

24 Stevens PM: Guided growth for angular correction. A preliminary series using a tension band plate. J Pediatr Orthop 2007;27:253-259.

25 Wills M: Orthopedic complications of childhood obesity. Pediatr Phys Ther 2004;16:230-235.

26 Krul M, van der Wouden JC, Schellevis FG, van Suijlekom-Smit LW, Koes BW: Musculoskeletal problems in overweight and obese children. Ann Fam Med 2009;7:352-356.

27 Wearing SC, Henning EM, Byrne NM, Steele JR, Hills AP: Musculoskeletal disorders associated with obesity: a biomechanical perspective. Obes Rev 2006;7:239-250.

28 Anandacoomarasamy A, Caterson I, Sambrook P, Fransen M, March L: The impact of obesity on the musculoskeletal system. Int J Obes (Lond) 2008;32:211-222.

-29 Widhalm HK, Marlovits S, Welsch GH, Dirisamer A, Neuhold A, van Griensven M, Seemann R, Vécsei V, Widhalm K: Obesity-related juvenile form of cartilage lesions: a new affliction in the knees of morbidly obese children and adolescents. Eur Radiol 2012;22/3:672-681.

- 30 Bafor A, Omota B, Ogbemudia A0: Correlation between clinical tibiofemoral angle and body mass index in normal Nigerian children. Int Orthop 2012;36:1247-1253.

31 Gibson K, Sayers SP, Minor MA: Measurement of varus/valgus alignment in obese individuals with knee osteoarthritis. Arthritis Care Res (Hoboken) 2010;62:690-696. 
-32 Paley D, Tetsworth K: Mechanical axis deviation of the lower limbs. Preoperative planning of uniapical angular deformities of the tibia or femur. Clin Orthop Relat Res 1992;280:48-64.

-33 Quatman CE, Ford KR, Myer GD, Paterno MV, Hewett TE: The effects of gender and pubertal status on generalized joint laxity in young athletes. J Sci Med Sport 2008;11:257-263.

-34 Gushue DL, Houck J, Lerner AL: Effects of childhood obesity on three-dimensional knee joint biomechanics during walking. J Pediatr Orthop 2005;25/6:763-768.

-35 Strutzenberger G, Richter A, Schneider M, Mündermann A, Schwameder H: Effects of obesity on the biomechanics of stair-walking in children. Gait Posture 2011;34:119-125.

-36 Turcot K, Armand S, Lübbeke A, Fritschy D, Hoffmeyer P, Suvà D: Does knee alignment influence gait in patients with severe knee osteoarthritis? Clin Biomech (Bristol, Avon) 2012;28/1:34-39.

-37 Macfarlane GJ, de Silva V, Jones GT: The relationship between body mass index across the life course and knee pain in adulthood: results from the 1958 birth cohort study. Rheumatology (Oxford) 2011;50:2251-2256.

-38 Felson DT, Niu J, Gross KD, Englund M, Sharma L, Cooke TD, Guermazi A, Roemer FW, Segal N, Goggins JM, Lewis CE, Eaton C, Nevitt MC: Valgus malalignment is a risk factor for lateral knee osteoarthritis incidence and progression: findings from the Multicenter Osteoarthritis Study and the Osteoarthritis Initiative. Arthritis Rheum 2012;65:355-362.

39 Scott AC: Treatment of infantile Blount disease with lateral tension band plating. J Pediatr Orthop 2012;32: 29-34.

40 Wiemann JM 4th, Tryon C, Szalay EA: Physeal stapling versus 8-plate hemiepiphysiodesis for guided correction of angular deformity about the knee. J Pediatr Orthop 2009;29:481-485.

41 Burghardt R, Specht S, Herzenberg JE: Mechanical failures of eight-plateguided growth system for temporary hemiepiphysiodesis. J Pediatr Orthop 2010;30:594-597.

42 Reilly JJ, Methven E, McDowell ZC, Hacking B, Alexander D, Stewart L, Kelnar CJ: Health consequences of obesity. Arch Dis Child 2003;88:748-752.

43 Yanovski JA: Pediatric obesity. Rev Endocr Metab Disord 2001;2:371-383.

-44 Centre for Public Health Excellence at NICE (UK); National Collaborating Centre for Primary Care (UK): Obesity: The Prevention, Identification, Assessment and Management of Overweight and Obesity in Adults and Children. London, National Institute for Health and Clinical Excellence (UK), 2006. www.ncbi.nlm.nih.gov/ books/NBK63696/.

45 Viner RM, White B, Barrett T, Candy DC, Gibson P, Gregory JW, Matyka K, Ong K, Roche E, Rudolf MC, Shaikh G, Shield JP, Wales JK: Assessment of childhood obesity in secondary care: OSCA consensus statement. Arch Dis Child Educ Pract Ed 2012;97:98-105.

46 Fried M, Hainer V, Basdevant A, Buchwald H, Deitel M, Finer N, Greve JW, Horber F, Mathus-Vliegen E, Scopinaro N, Steffen R, Tsigos C, Weiner R, Widhalm K: Interdisciplinary European guidelines on surgery of severe obesity. Obes Facts 2008;1:52-59.

47 Reinehr T, Widhalm K, l'Allemand D, Wiegand S, Wabitsch M, Holl RW; APV-Wiss STudy Group and German Competence Net Obesity: Two-year follow-up in 21,784 overweight children and adolescents with lifestyle intervention. Obesity (Silver Spring) 2009;17:1196-1199.

48 Shultz SP, Anner J, Hills AP: Paediatric obesity, physical activity and the musculoskeletal system. Obes Rev 2009;10:576-582. 